\title{
Observations of High Nitrate Concentrations in Forage Bermudagrass during Severe to Exceptional Drought Years
}

\author{
Dennis W. Hancock ${ }^{1}$, Uttam K. Saha², Jennifer J. Tucker ${ }^{3}$, R. Lawton Stewart Jr. ${ }^{4^{*}}$ \\ ${ }^{1}$ Department of Crop and Soil Sciences, University of Georgia, Athens, USA \\ ${ }^{2}$ Feed and Environmental Water Laboratory, University of Georgia, Athens, USA \\ ${ }^{3}$ Department of Animal and Dairy Sciences, University of Georgia, Tifton, USA \\ ${ }^{4}$ Department of Animal and Dairy Sciences, University of Georgia, Athens, USA \\ Email: "lawtons@uga.edu
}

Received 20 January 2016; accepted 27 March 2016; published 30 March 2016

Copyright (C) 2016 by authors and Scientific Research Publishing Inc.

This work is licensed under the Creative Commons Attribution International License (CC BY).

http://creativecommons.org/licenses/by/4.0/

c) (i) Open Access

\begin{abstract}
With the prediction of climate change-induced increases in drought frequency and severity in the southeastern USA, it is important to better understand the risks that drought may pose to $\mathrm{NO}_{3}$ accumulation in bermudagrass [Cynodon dactylon (L.) Pers.] forage. This report offers observations of $\mathrm{NO}_{3}$ concentration in Bermudagrass forage samples submitted to the University of Georgia's Feed and Environmental Water Lab (FEWL) during the extreme to exceptional drought of 2007, the severe drought of 2008 , and the four preceding seasons when drought stress was minimal or absent. The probability $(P)$ of a sample being at high risk for nitrate toxicosis was the greatest for the extreme to exceptional drought of $2007(P=0.160)$, slightly lower in the severe drought year of $2008(P=0.105)$, and the lowest for samples from the 2003-2006 growing seasons $(P=0.082)$ when drought stress was minimal or absent.
\end{abstract}

\section{Keywords}

Nitrates, Drought, Bermudagrass

\section{Introduction}

Global climate change is expected to cause an increase in frequency and severity of drought in the southeastern United States during the next century [1]. One of the risks posed to forage production by an increased frequency

*Corresponding author.

How to cite this paper: Hancock, D.W., Saha, U.K., Tucker, J.J. and Stewart Jr., R.L. (2016) Observations of High Nitrate Concentrations in Forage Bermudagrass during Severe to Exceptional Drought Years. American Journal of Plant Sciences, 7, 695-701. http://dx.doi.org/10.4236/ajps.2016.74062 
and severity of drought in this region would be the potential for a toxic build-up of nitrate-nitrogen $\left(\mathrm{NO}_{3}-\mathrm{N}\right)$ concentrations in the forage crops common to this region [2]. Ruminants that consume a diet consisting of more than $2500 \mathrm{mg} \mathrm{NO}_{3} \mathrm{~kg}^{-1}$ are at risk of developing abnormally high concentrations of nitrite in their bloodstream, leading to the formation of methemoglobinemia. This, consequently, can result in condition commonly referred to as nitrate toxicosis. Nitrate levels higher than $4500 \mathrm{mg} \mathrm{NO}_{3} \mathrm{~kg}^{-1}$ pose a risk of chronic nitrate toxicosis and, in some situations, animal death [2].

Bermudagrass [Cynodon dactylon (L.) Pers.] is the most widely used warm season perennial grass for pasture and hay production in the southern USA, and it is noted for its drought tolerance and high water use efficiency [3]. Further, bermudagrass is highly efficient at using $\mathrm{N}$ and most of the nitrate reductase activity occurs in its roots [4]. Though this may reduce its risk in accumulating toxic concentrations of $\mathrm{NO}_{3}$ [5], there is sufficient evidence to suggest that toxic $\mathrm{NO}_{3}$ levels in bermudagrass do frequently occur [6]-[10]. However, it is unclear how frequent one might expect to find bermudagrass forage samples to be high in nitrates, especially during severe to exceptionally severe drought.

Recent weather conditions in Georgia (USA) have granted a unique opportunity to make observations about the propensity for $\mathrm{NO}_{3}$ accumulation in bermudagrass. The National Drought Mitigation Center's U.S. Drought Monitor classified a large majority of the state of Georgia in their extreme (D3) to exceptional (D4) drought categories during the 2007 growing season and at least a severe (D2) drought during 2008 ([11]; Figure 1). These years had been preceded by four years of relatively little prolonged drought stress. In each of these years, a substantial number of forage samples were being submitted for forage quality and nitrate analysis at the University of Georgia's Feed and Environmental Water Lab (FEWL). As a result, a very large and robust database exists that could provide insight into the nitrate concentration characteristics of forage submissions made during drought years and years when drought stress during the growing season was absent or much less pronounced. Thus, the objective of this work was to offer in actu observations from the University of Georgia's FEWL on the nitrate concentration of bermudagrass forage samples submitted during the drought years of 2007 and 2008 and the four preceding seasons when drought stress was minimal or absent.

\section{Materials and Methods}

This study uses observations obtained from the analyses of bermudagrass forage samples submitted to the University of Georgia's FEWL from 1 July 2003 through 31 March 2009. The data were first screened to include only those samples that had been analyzed for $\mathrm{NO}_{3}$ concentration, which is determined in the FEWL by a colorimetric analysis of the nitration of salicylic acid [12]. Data were further screened to eliminate samples from areas that had not experienced similar levels of drought stress during 2007 and 2008. Pasture condition reports

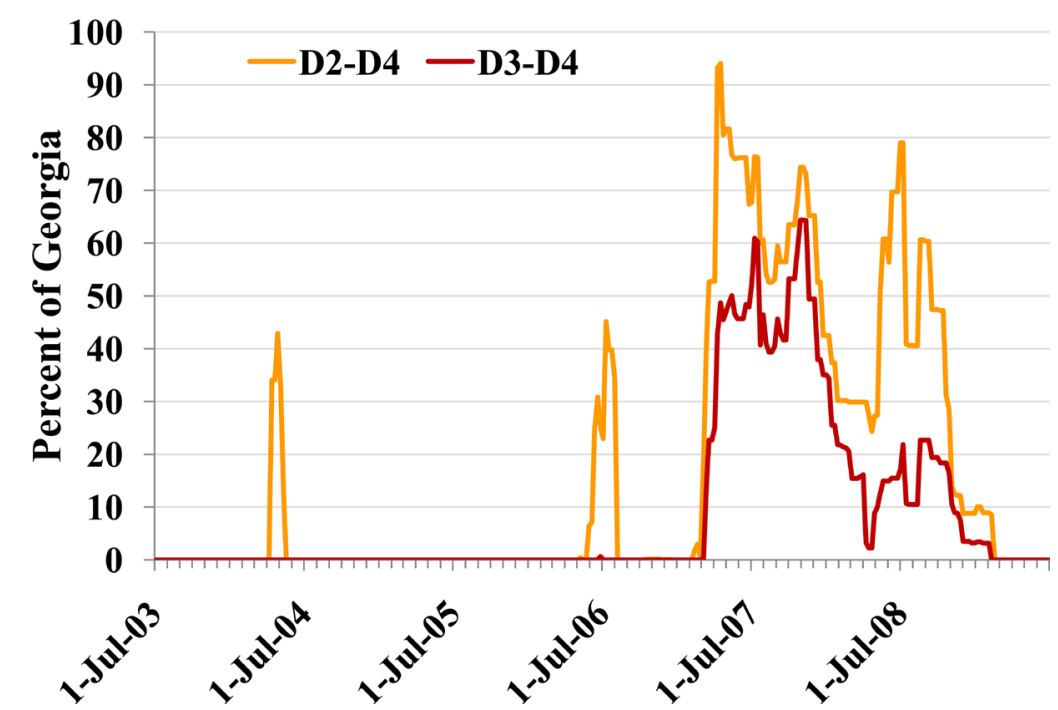

Figure 1. The percent of the state of Georgia (USA) that was classified by the national drought mitigation center's U.S. drought monitor (2009) as being in extreme to exceptional (D3-D4) and severe to exceptional (D2-D4) drought categories between 1 July 2003 and 30 June 2009. 
from the USDA-National Agricultural Statistics Service (NASS) indicated that drought conditions were not consistently severe in Georgia's counties along the Atlantic Coast during 2007 and 2008. Therefore, all observations from the 17 counties in the NASS's Georgia District-9 were screened from each year used in this analysis.

Next, the data were segregated into growing seasons based on sample submission date, using an assumption that bermudagrass from an individual growing season would be submitted between 1 June of that same year and 31 March of the following year. For example, bermudagrass samples submitted between 1 June 2007 and 31 March 2008 were categorized into the "2007" growing season category. All other observations falling outside of this time frame (i.e., with a sample submission date of 1 April through 31 May) were excluded from the analysis. Samples submitted from the 2003, 2004, 2005, and 2006 seasons were originally subjected to an analysis similar to that described below but were found to not differ $(P>0.10)$ from one another (data not shown). Because of their similarity and indications from U.S. Drought Monitor data that bermudagrass forage produced during this period was largely free from severe drought stress, the observations from the 2003, 2004, 2005, and 2006 growing seasons were combined into one large category (“2003-2006”).

Using the UNIVARIATE procedure in SAS [13], the screened nitrate data were found to exhibit significant skewness and kurtosis (Table 1) and, therefore, violated assumptions of normality. Consequently, the data were subjected to a natural logarithmic transformation. Further, approximately $20 \%$ of the observations in the complete database were found to have nitrate levels below the $100 \mathrm{mg} \mathrm{NO}_{3} \mathrm{~kg}^{-1}$ detection limit. These observations of nitrate levels below the detection limit are known as left-censored data and were included in this analysis by employing a survival analysis technique. In this technique, the censored data are kept in the analysis but are treated differently from actual observed values. Specifically, it is assumed that there is a latent variable $Y^{*}$ for the $i$-th observation which is the actual $\mathrm{NO}_{3}$ concentration in the natural log scale, while $Y_{i}$ is the detected natural log transformed $\mathrm{NO}_{3}$ concentration. The model can be expressed using Equations (1) to (3), and used within the LIFEREG procedure in SAS [13], which is used to fit survival data.

$$
\begin{gathered}
Y_{i}^{*}=\beta_{0}+\beta_{1} I\{\text { year }=2007\}+\beta_{2} I\{\text { year }=2008\}+\epsilon_{i}, \epsilon_{i} \sim N\left(0, \sigma^{2}\right) ; \\
Y_{i}=Y_{i}^{*} \text { if } Y_{i}^{*}>\ln (100) \\
Y_{i}=\ln (100) \quad \text { if } Y_{i}^{*} \leq \ln (100)
\end{gathered}
$$

where $\beta_{0}, \beta_{0}+\beta_{1}$, and $\beta_{0}+\beta_{2}$ are the means of the true ln transformed $\mathrm{NO}_{3}$ concentrations in the null, 2007, and 2008 growing season categories, respectively; $I$ year $=2007\}$ is an indicator variable which is 1 for growing season 2007 and 0 for other growing seasons and $I$ year $=2008\}$ is an indicator variable which is 1 for growing season 2008 and 0 for other growing seasons (i.e., for the null growing seasons, the two indicator variables are both zero).

In order to compare the frequency of having moderate or highly risky $\mathrm{NO}_{3}$ concentrations within the growing season categories, the probabilities of these occurrences during the individual growing seasons were calculated. This was done by first grouping the bermudagrass samples into three categories of toxicity risk based on their $\mathrm{NO}_{3}$ concentration: Low Risk (LR), where nitrate levels were less than $2500 \mathrm{mg} \mathrm{NO}_{3} \mathrm{~kg}^{-1}$; Moderate Risk (MR), where nitrate levels were $2500-4500 \mathrm{mg} \mathrm{NO}_{3} \mathrm{~kg}^{-1}$; and High Risk (HR), where nitrate levels greater than 4500 mg $\mathrm{NO}_{3} \mathrm{~kg}^{-1}$. Because the three levels are ordinal, a cumulative logistic model [14] was used to estimate the log (base $e$ ) probability $(P)$ of a bermudagrass forage sample being in a particular risk category in the 2003-2006,

\begin{tabular}{|c|c|c|c|c|c|c|}
\hline Growing season & $n$ & $\begin{array}{c}\text { Range } \\
\mathrm{mg} \mathrm{NO}_{3} \mathbf{~ k g}^{-1}\end{array}$ & Skewness & Kurtosis & $W^{\dagger}$ & $D^{\ddagger}$ \\
\hline 2003-2006 & 2533 & $N D^{\S}-18,647$ & 1.969 & 5.385 & - & $0.258^{* *}$ \\
\hline 2007 & 1010 & ND - 17,804 & 2.503 & 8.507 & $0.808^{* * *}$ & $0.181^{* *}$ \\
\hline 2008 & 869 & ND - 17,012 & 2.981 & 12.623 & $0.716^{* * *}$ & $0.238^{* *}$ \\
\hline
\end{tabular}

Table 1. Distribution characteristics of the observations used in the analysis of the $\mathrm{NO}_{3}$ concentrations in bermudagrass forage samples submitted to the UGA-FEWL during the 2003-2006, 2007, and 2008 growing season categories.

\footnotetext{
${ }^{* *},{ }^{* * *}$ Significant at the $0.05,0.01$, and 0.001 probability levels, respectively. ${ }^{\dagger} W=$ the Shapiro-Wilk test statistic, which is appropriate for characteriz-
} ing datasets when $n \geq 2000$. ${ }^{\ddagger} D=$ Kolmogorov-Smirnov statistic. ${ }^{\S} \mathrm{ND}=$ not detectable. 
2007, and 2008 growing seasons. Specifically, Equation (4) presents the cumulative logistic model for the log odds that was analyzed using the LOGISTIC procedure in SAS (SAS Institute, 2004).

$$
\log \text { odds }_{j}=\alpha_{j}+\tau_{1} I\{\text { year }=2007\}+\tau_{2} I\{\text { year }=2008\}, j=1,2
$$

where the cumulative logits are defined as Equations ((5) and (6)).

$$
\begin{gathered}
\log \text { odds }_{1}=\operatorname{logit}[P(\geq M R)]=\ln \frac{P(\geq M R)}{1-P(\geq M R)}=\ln \frac{P(M R)+P(H R)}{1-P(M R)-P(H R)} \\
\log \text { odds }_{2}=\operatorname{logit}[P(H R)]=\ln \frac{P(H R)}{P(L R)+P(M R)}=\ln \frac{P(H R)}{1-P(H R)}
\end{gathered}
$$

where intercepts $\alpha_{1}$ and $\alpha_{2}$ are associated with $\log o d d s_{1}$ and $\log$ odds $s_{2}$ (as defined above), respectively, and have the interpretation of log odds in the 2003-2006 growing seasons, $\tau_{1}$ is the increment to the log odds in the 2007 growing season, and $\tau_{2}$ is the increment to the log odds in the 2008 growing season; where $I$ \{year $=2007$ \} is an indicator variable that equals 1 for the 2007 growing season and 0 for other growing seasons and $I$ \{year $=2008$ \} is an indicator variable that equals 1 for growing season 2008 and 0 for other growing seasons (i.e., for the 2003-2006 growing seasons, the two indicator variables are both zero); and where it is given, as defined in Equation (7), that the probabilities for each risk category in a given year sum to equal 1.

$$
P(L R)+P(M R)+P(H R)=1
$$

For each growing season category (2003-2006, 2007, and 2008), the estimated parameters from Equation (4) were used in Equation (5) to calculate the probability of $M R$ or greater $[P(\geq M R)]$ concentrations of $\mathrm{NO}_{3}$ in the submitted forage samples. Similarly, these model parameters were then used in Equation (6) to calculate the probability of $H R[P(H R)]$ concentrations of $\mathrm{NO}_{3}$ in the sample submissions for each growing season category. The probability of $M R[P(M R)] \mathrm{NO}_{3}$ concentrations was derived by subtracting $P(H R)$ from $P(\geq M R)$. Then the probability of $L R[P(L R)] \mathrm{NO}_{3}$ concentrations was derived from Equation (7) using the estimates of $P(H R)$ and $P(M R)$.

\section{Results and Discussion}

\subsection{In Actu Observations of Nitrate Concentrations in Bermudagrass}

The results of the analysis of maximum likelihood estimates for $\beta_{0}, \beta_{1}$, and $\beta_{2}$ indicated that all parameters were significantly $(P<0.01)$ greater than zero (Table 2). Since $\beta_{0}, \beta_{0}+\beta_{1}$, and $\beta_{0}+\beta_{2}$ are estimates of the means of the true natural $\log$ transformed $\mathrm{NO}_{3}$ concentrations during the 2003-2006, 2007, and 2008 growing season categories, respectively, these estimates were calculated and transformed back to the original units (Table 3). The mean concentration of $\mathrm{NO}_{3}$ in samples submitted during the 2003-2006 growing seasons $\left(512 \mathrm{mg} \mathrm{NO}_{3} \mathrm{~kg}^{-1}\right)$ was significantly lower $(P<0.05)$ than in samples submitted from the drought-stressed season of $2008\left(626 \mathrm{mg} \mathrm{NO}_{3}\right.$ $\mathrm{kg}^{-1}$ ), and both were significantly lower than those from the extreme to exceptional drought-stressed season in 2007 (1170 $\mathrm{mg} \mathrm{NO}_{3} \mathrm{~kg}^{-1}$ ). Though these mean values are considerably lower than those expected to pose a moderate (2500 mg NO $\mathrm{kg}^{-1}$ ) or high (4500 $\left.\mathrm{mg} \mathrm{NO}_{3} \mathrm{~kg}^{-1}\right)$ risk of nitrate toxicosis [2], each growing season had a substantial number of samples with $\mathrm{NO}_{3}$ concentrations that would be considered moderate or highly risky (Table 4).

\subsection{Estimates of the Probability of Low, Moderate, and High Nitrate Concentrations}

To compare the frequency of moderate or highly risky $\mathrm{NO}_{3}$ concentrations across growing season categories, the probabilities of these occurrences during the individual growing seasons were calculated. The results of the analysis of maximum likelihood estimates for parameters $\alpha_{1}, \alpha_{2}, \tau_{1}$, and $\tau_{2}$ used in Equation (4) indicated that each of the parameters was significantly different $(P<0.01)$ from zero (Table 5$)$. These parameters were used to estimate the probabilities of $L R, M R$, and $H R$ concentrations of $\mathrm{NO}_{3}$ in bermudagrass forage sample submissions during the 2003-2006, 2007, and 2008 growing seasons (Table 6).

In each of the three growing seasons, there existed a high probability $(P>0.65)$ that a bermudagrass forage sample would be classified as $L R$. However, this probability differed between each growing season category, 
Table 2. Results of the analysis of maximum likelihood estimates for $\beta_{0}, \beta_{0}+\beta_{1}$, and $\beta_{0}+\beta_{2}$, which are parameters in the models (Equations (1) to (3)) that estimate the means of the true $\log$ (base $e$ ) transformed $\mathrm{NO}_{3}$ concentrations during the 2003-2006 (null), 2007, and 2008 growing season categories, respectively.

\begin{tabular}{cccccc}
\hline Parameter & Estimate & $95 \%$ CI & SE & $\chi^{2}$ & $P>\chi^{2}$ \\
\hline$\beta_{0}$ & 6.237 & \pm 0.066 & 0.034 & $34,303.4$ & $<0.0001$ \\
$\beta_{1}$ & 0.827 & \pm 0.122 & 0.062 & 177.59 & $<0.0001$ \\
$\beta_{2}$ & 0.196 & \pm 0.130 & 0.066 & 8.78 & 0.0030 \\
\hline
\end{tabular}

Table 3. Means and 95\% confidence intervals for the $\mathrm{NO}_{3}$ concentrations during the 2003-2006, 2007, and 2008 growing season categories.

\begin{tabular}{cccc}
\hline Growing season & Mean & $\mathbf{9 5 \% ~ C I ~}$ & \multicolumn{1}{c}{ SE } \\
\cline { 2 - 4 } & & $\mathrm{mg} \mathrm{NO}_{3} \mathrm{~kg}^{-1}$ & 16.79 \\
$2003-2006$ & $512^{\mathrm{a} \dagger}$ & \pm 32.6 & 102.09 \\
2007 & $1170^{\mathrm{c}}$ & \pm 200.1 & 56.33 \\
\hline
\end{tabular}

${ }^{\dagger}$ Same letters within column are not significantly different at $P<0.05$.

Table 4. The frequency with which bermudagrass forage samples submitted to the UGA-FEWL were at low, moderate, and high risk for nitrate toxicosis during the 2003-2006, 2007, and 2008 growing seasons.

\begin{tabular}{|c|c|c|c|}
\hline Growing season & $\begin{array}{c}\text { Low risk } \\
\left(<2500 \mathrm{mg} \mathrm{NO}_{3} \mathrm{~kg}^{-1}\right)\end{array}$ & $\begin{array}{c}\text { Moderate risk } \\
\left(2500-4500 \mathrm{mg} \mathrm{NO}_{3} \mathrm{~kg}^{-1}\right)\end{array}$ & $\begin{array}{c}\text { High risk } \\
\left(>4500 \mathrm{mg} \mathrm{NO}_{3} \mathrm{~kg}^{-1}\right)\end{array}$ \\
\hline \multirow{2}{*}{ 2003-2006 } & $80.3 \%$ & $11.2 \%$ & $8.5 \%$ \\
\hline & $(2034 / 2533)$ & $(284 / 2533)$ & $(215 / 2533)$ \\
\hline \multirow{2}{*}{2007} & $65.2 \%$ & $19.6 \%$ & $15.1 \%$ \\
\hline & $(659 / 1010)$ & $(198 / 1010)$ & $(153 / 1010)$ \\
\hline \multirow{2}{*}{2008} & $75.8 \%$ & $13.3 \%$ & $10.8 \%$ \\
\hline & (659/869) & $(116 / 869)$ & $(94 / 869)$ \\
\hline
\end{tabular}

Table 5. Results of the analysis of maximum likelihood estimates for $\alpha_{1}, \alpha_{2}, \tau_{1}$, and $\tau_{2}$, which are parameters in the models (Equations (4) to (6)) used to estimate the probability of low, moderate, and high risk $\mathrm{NO}_{3}$ concentrations during the 2003-2006, 2007, and 2008 growing season categories in Table 6.

\begin{tabular}{cccccc}
\hline Parameter & Estimate & $95 \%$ CI & SE & Wald $\chi^{2}$ & $P>\chi^{2}$ \\
\hline$\alpha_{1}$ & -1.402 & \pm 0.097 & 0.0497 & 793.7724 & $<0.0001$ \\
$\alpha_{2}$ & -2.411 & \pm 0.120 & 0.0614 & 1541.714 & $<0.0001$ \\
$\tau_{1}$ & 0.756 & \pm 0.160 & 0.0817 & 85.5141 & $<0.0001$ \\
$\tau_{2}$ & 0.263 & \pm 0.182 & 0.0928 & 8.0623 & 0.0045 \\
\hline
\end{tabular}

Table 6. The calculated probability (and 95\% confidence intervals) of a submitted bermudagrass forage sample being categorized as a low, moderate, and high risk for nitrate toxicosis during the 2003-2006, 2007, and 2008 growing seasons.

\begin{tabular}{|c|c|c|c|c|c|c|}
\hline \multirow{2}{*}{$\begin{array}{c}\text { Growing season } \\
2003-2006\end{array}$} & \multicolumn{2}{|c|}{$\begin{array}{c}\text { Low risk } \\
\left(<2500 \mathrm{mg} \mathrm{NO}_{3} \mathrm{~kg}^{-1}\right)\end{array}$} & \multicolumn{2}{|c|}{$\begin{array}{c}\text { Moderate risk } \\
\left(2500-4500 \mathrm{mg} \mathrm{NO}_{3} \mathrm{~kg}^{-1}\right)\end{array}$} & \multicolumn{2}{|c|}{$\begin{array}{c}\text { High risk } \\
\left(>4500 \mathrm{mg} \mathrm{NO}_{3} \mathrm{~kg}^{-1}\right)\end{array}$} \\
\hline & 0.802 & \pm 0.0159 & 0.115 & \pm 0.0063 & 0.082 & \pm 0.0086 \\
\hline 2007 & 0.656 & \pm 0.0602 & 0.184 & \pm 0.0213 & 0.160 & \pm 0.0342 \\
\hline 2008 & 0.757 & \pm 0.0549 & 0.138 & \pm 0.0231 & 0.105 & \pm 0.0251 \\
\hline
\end{tabular}

with the highest probability occurring in the more "typical” growing seasons of 2003-2006 (0.802 \pm 0.0159$)$, followed by the severe drought season of 2008 (0.757 \pm 0.0549$)$, and with the lowest probability occurring in the extreme to exceptional drought of $2007(0.656 \pm 0.0602)$. The most concerning issue revealed in this compari- 
son was that samples submitted from the 2007 growing season were 1.95 times $(0.160 / 0.082)$ more likely to be in the high risk category than in the "normal" growing seasons of 2003-2006. Though this also tended $(P<0.10)$ to occur in 2008, it was not as likely as in 2007.

\subsection{Limitations, Additional Key Findings, and the Need for Additional Research}

It is important to note that our results should not be interpreted as establishing the expected mean $\mathrm{NO}_{3}$ concentration of samples from similar seasons or number of observations in $L R, M R$, and $H R$ categories during drought. Our analysis was performed on producer-submitted bermudagrass forage samples. It is likely that producers were more apt to identify and submit forage samples from bermudagrass lots that may have been at an increased risk of nitrate toxicity during the droughts of 2007 and 2008. This may have increased the observed mean and altered the distribution of $\mathrm{NO}_{3}$ concentrations in the samples from these seasons. Even so, this analysis has shown that high risk samples do frequently occur and that this may even occur in samples from growing seasons that were not severely drought stressed (Table 1, Table 4, and Table 6).

Moreover, these observations indicate that $\mathrm{NO}_{3}$ may accumulate in bermudagrass to a much higher level than previously thought. Of the published work that reports $\mathrm{NO}_{3}$ concentration in forage bermudagrass [6]-[9], the highest reported level was $8350 \mathrm{mg} \mathrm{NO}_{3} \mathrm{~kg}^{-1}$ [8]. In the 2003-2006 growing seasons when relatively little prolonged drought stress was present, we observed that $1.86 \%(47 / 2533)$ of the samples had $\mathrm{NO}_{3}$ concentrations greater than $8350 \mathrm{mg} \mathrm{NO}_{3} \mathrm{~kg}^{-1}$. In the extreme to exceptional drought of 2007 and the severe drought season of 2008, we observed that 3.47\% (35/1010) and 2.30\% (20/869) of the bermudagrass samples submitted from those respective growing seasons exceeded this previously reported high.

The degree to which drought stress influences $\mathrm{NO}_{3}$ concentrations in forage bermudagrass will need to be assessed in well-designed field trials. For example, this additional research should include an assessment of the influence of $\mathrm{N}$ fertilizer application strategies (e.g., splitting the applied $\mathrm{N}$ equally across multiple applications, the use of "enhanced-efficiency" and slow/controlled-released fertilizers, etc.) so that an assessment can be made of the degree to which $\mathrm{N}$ management interacts with the growing season conditions to influence the development of toxic $\mathrm{NO}_{3}$ concentrations in bermudagrass.

\section{Acknowledgements}

The authors thank Dr. Jien Chen, Associate Director of the University of Georgia's Statistical Consulting Center, for her assistance with the statistical analysis performed for this paper.

\section{References}

[1] Karl, T.R., Melillo, J.M. and Peterson, T.C. (2009) Global Climate Change Impacts in the United States: A State of Knowledge Report from the U.S. Global Change Research Program. Cambridge University Press, Cambridge.

[2] Wright, M.J. and Davison, K.L. (1964) Nitrate Accumulation in Crops and Nitrate Poisoning in Animals. Advances in Agronomy, 16, 197-247. http://dx.doi.org/10.1016/S0065-2113(08)60025-5

[3] Taliaferro, C.M., Rouquette Jr., F.M. and Mislevy, P. (2004) Bermudagrass and Stargrass. In: Moser, L., Sollenberger, L. and Burson, B., Eds., Warm-Season (C4) Grasses, Monograph No. 45. American Society of Agronomy, Crop Science Society of America, Soil Science Society of America, Madison, 417-475.

[4] Jiang, Z., Hull, R.J. and Sullivan, W.M. (2002) Nitrate Uptake and Reduction in C3 and C4 Grasses. Journal of Plant Nutrition, 25, 1303-1314. http://dx.doi.org/10.1081/PLN-120004390

[5] Hojjati, S.M., Taylor, T.H. and Templeton, W.C. (1972) Nitrate Accumulation in Rye, Tall Fescue, and Bermudagrass as Affected by Nitrogen Fertilization. Agronomy Journal, 64, 624-627. http://dx.doi.org/10.2134/agronj1972.00021962006400050023x

[6] Burns, J.C., Wagger, M.G. and Fisher, D.S. (2009) Animal and Pasture Productivity of “Coastal” and "Tifton 44” Bermudagrass at Three Nitrogen Rates and Associated Soil Nitrogen Status. Agronomy Journal, 101, 32-40. http://dx.doi.org/10.2134/agronj2008.0006x

[7] Burns, J.C., King, L.D. and Westerman, P.W. (1990) Long-Term Swine Lagoon Effluent Applications on “Coastal” Bermudagrass. I. Yield, Quality, and Element Removal. Journal of Environmental Quality, 19, 749-756. http://dx.doi.org/10.2134/jeq1990.00472425001900040019x

[8] Rouquette Jr., F.M. and Keisling, T.C. (1980) Nitrate Content of Four Bermudagrasses. In: Forage Research in Texas. Rep. 80-86, Texas Agricultural Experiment Station, College Station, 118-121. 
[9] Lund, Z.F., Doss, B.D. and Lowry, F.E. (1975) Dairy Cattle Manure-Its Effect on Yield and Quality of Coastal Bermudagrass (Cynodon dactylon). Journal of Environmental Quality, 4, 358-362. http://dx.doi.org/10.2134/jeq1975.00472425000400030016x

[10] Lovelace, D.A., Holt, E.C. and Anderson, W.B. (1968) Nitrate and Nutrient Accumulation in Two Varieties of Bermudagrass (Cynodon dactylon (L.) Pers.) as Influenced by Soil-Applied Fertilizer Nutrients. Agronomy Journal, 60, 551-554. http://dx.doi.org/10.2134/agronj1968.00021962006000050032x

[11] U.S. Drought Monitor (2009) Drought Monitor Archives. http://www.drought.unl.edu/dm/dmtabs_archive.htm

[12] Cataldo, D.A., Haroon, M., Shrader, L.E. and Youngs, V.L. (1975) Rapid Colorimetric Determination of Nitrate in Plant Tissue by Nitration of Salicylic Acid. Communications in Soil Science and Plant Analysis, 6, 71-80. http://dx.doi.org/10.1080/00103627509366547

[13] SAS Institute (2004) SAS/STAT 9.1 User’s Guide. SAS Inst., Cary.

[14] Agresti, A. (1990) Categorical Data Analysis. Wiley, New York, 322-330. 